\title{
Assessing the functional polycentricity of the mega-city region of Central Belgium based on advanced producer service transaction links
}

\author{
H. Hanssens ${ }^{*}$, B. Derudder ${ }^{+}$, S. Van Aelst ${ }^{x}$, F. Witlox ${ }^{++}$ \\ ${ }^{*},+,++$ Department of Geography, Ghent University, Krijgslaan 281(S8), B-9000 Ghent, Belgium \\ ${ }^{\times}$Department of Applied Mathematics and Computer Science, Ghent University, Krijgslaan 281(S9), B- \\ 9000 Ghent, Belgium
}

\begin{abstract}
This paper comments on three aspects of POLYNET's implementation of the GaWC model to measure functional polycentricity at the local scale. These aspects are: (i) the use of APS office locations as a proxy for inter-city relations, (ii) the problematic calculation of the functional polycentricity index, and (iii) the rather narrow conceptualization of functional polycentricity. Alternative methodologies are introduced and implemented based on transaction link data to examine whether Central Belgium displays features of a functionally polycentric mega-city region. The results suggest that this is not the case. When it comes to service procurement by large companies in Belgium, Central Belgium displays more features of a hierarchical urban system with Brussels as dominant service city than of a functionally polycentric urban system. We do, however, find some indications for preliminary urban network formation.
\end{abstract}

Key words: Central Belgium, mega-city region, functional polycentricity, transaction links, gravity mode

\footnotetext{
* Corresponding author.

Email address: heidi.hanssens@ugent.be

Telephone: +3292644697

Fax: +32 92644985
} 


\section{Introduction}

One of the many spatial structures associated with the nexus between globalization processes and urban change has been the development of a new type of urban form, formally known under a wide range of labels such as multi-core metropolis (HALL, 1999); global city-regions (SCOTT, 2001); polycentric urban regions (KLOOSTERMAN and MUSTERD, 2001); and - as applied in the present paper mega-city regions (MCR; HALL and PAIN, 2006). Although the various terminologies differ in specific meaning and regional scope, they do share some core features of what constitutes this new type of urban form (HOYLER et al., 2008): it is spread out over a large area, contains a number of physically separate but functionally networked cities and towns that are more or less at commuting distance and clustered around one or several larger central cities, and is/is increasingly becoming to some degree polycentric in that (i) there is no dominant city and (ii) there is considerable regional cohesion in personal occupational and corporate relationships of people, organizations, and firms (KLOOSTeRman and Musterd, 2001; HAlL and PAIN, 2006; HOYLer et al., 2008; DE Goel et al., 2010).

Acknowledging the mounting importance of MCRs and the many challenges as well as economic opportunities they entail, the European Commission - through the INTERREG IIIB project - has invested in what has probably been the most comprehensive and elaborate research effort on the subject so far, namely the POLYNET project. Building theoretically on (i) SASSEN'S (2001) global city concept; (ii) the world city network (WCN) model devised by the Globalization and World Cities (GaWC, http://www.lboro.ac.uk/gawc) research group (DERUDDER et al., 2003; TAYLOR 2001, 2004; TAYLOR and ARANYA, 2008); (iii) the literature on global city regions (SCOTT, 2001); and (iv) CASTELLS' (1996) space of flows, the POLYNET project has studied flows of information, people, knowledge... in the advanced producer services (APS) ${ }^{1}$ sector to quantitatively and qualitatively measure inter-city relations both within eight North West European MCRs and beyond their boundaries (HALL and PAIN, 2006).

Although POLYNET has made a valuable contribution to our understanding of contemporary urban systems in North West Europe, several critical reflections can be made. In this paper, we comment on three issues that are related to POLYNET's implementation of the GaWC model to measure functional polycentricity at the local scale. These issues are (i) the use of APS office locations as proxy for inter-city relations instead of measuring actual urban links, (ii) the problematic calculation of the functional polycentricity index (FPI), and (iii) the rather narrow conceptualization of functional polycentricity. The formative aim of this paper is to address these three issues with the overall objective to arrive at a more adequate measurement of polycentricity. Developing more suitable measurements of functional integration of MCRs is not only relevant on its own terms (MEIJERS, 2008), but also because research on polycentric development serves as the input to broader research questions altogether. MEIJERS and BURGER (2010), for instance, have shown how different spatial structures - and in particular the monocentricity/polycentricity dimension - affect the economic performance of metropolitan areas. Here we focus on the three above-mentioned issues, and tackle these by (i) introducing an alternative approach to measure polycentricity based on actual transaction link data, (ii) developing an alternative method to calculate the FPI, and (iii) extending the conceptualization of functional polycentricity by introducing a formal model to test the degree of urban network integration. These alternative methods are implemented to a specific case-study in which we assess the functional polycentricity of the MCR of Central Belgium through the lens of APS procurement by Belgium's top-300 companies.

The remainder of the paper is structured as follows. Section 2 starts with a brief discussion of the GaWC methodology implemented in the POLYNET project. We begin by outlining the conceptualization of functional polycentricity that underlies this methodology, and then describe the specifications of the GaWC model and the way in which functional polycentricity is measured. The second part of section 2 provides a detailed account of the three critical reflections referred to 
above, and makes some preliminary suggestions for alternative methodologies. These alternative methodologies are then discussed and implemented to our case-study in sections 3, 4 and 5 of this paper. Section 3 describes our methodology for collecting transaction link data, section 4 develops and implements an alternative method to calculate the FPI, and section 5 introduces a formal model to test the degree of urban network formation. In the conclusions, we present a critical overview of our main findings and outline some avenues for future research.

\section{Measuring functional polycentricity based on APS office location data}

\subsection{The GaWC model extended to the local scale}

To explore the structure and dynamics of the eight European MCRs and assess their functional polycentricity, POLYNET measures amongst others the extent to which the constituent cities are equally connected to an urban network of knowledge flows. In doing so, POLYNET assumes an interpretation of functional polycentricity as described and defined by BURGER and MEIJERS (2012). In their paper, the authors initially distinguish between multicentricity and polycentricity in that the latter concept - apart from the obvious existence of multiple centres - also involves a certain balance in importance of these centres.

A fundamental difference of opinion in the existing literature relates to how this 'importance' can and should be measured. In general, polycentricity is analyzed either in terms of absolute importance (i.e. nodality) of centres or in terms of relative importance (i.e. centrality) of centres. The former approach, referred to as morphological polycentricity, makes use of static attributes (e.g. employment, population) to quantify the importance of a city. The latter approach, referred to as functional polycentricity, makes use of relational data (e.g. commuting, shopping trips, or - in the case of POLYNET - flows of knowledge). Based on these definitions, it follows that a functionally polycentric MCR is one in which there is a certain balance in the relative importance or centrality of the constituent centres. Assessing the functional polycentricity of a MCR thus constitutes two steps: (i) quantifying the centrality of each centre; and (ii) combining these measures into one single index to compute the degree of balance.

To quantify the centrality of a city in an urban network of knowledge flows, POLYNET implements the GaWC methodology - originally devised to measure the world city network (WCN) - and extends its scope to the regional scale (TAYLOR et al., 2006, 2008, 2009). In this approach, the urban network is specified as an interlocking network with three levels (TAYLOR, 2001): a network level (i.e. cities connected in world economy), a nodal level (i.e. cities), and a sub-nodal level (i.e. firms providing APS). It is at the latter level that network formation takes place. Through their attempts to provide a seamless service to their clients across the world, and given their dependency on urbanization economies, APS firms have created global networks of offices in cities around the world. One of the basic assumptions in the model, then, is that cities are inter-linked by intra-firm flows of information and knowledge as projects for international clients require multiple inputs. Globalized APS firms are thus taken to be the prime producers of the urban network, and their multiple office locations can be used as a proxy for inter-city flows of information.

The model can be formally represented by a matrix $V$ defined by $n$ cities $X m$ firms where $v_{i j}$ is the 'service value' of city $i$ to firm $j$. The service value is the importance of a city to a firm's office network and depends upon the size and functions of an office or offices in a city. The global network connectivity $\mathrm{GNC}_{\mathrm{a}}$ of city $a$ in this interlocking network is computed by transforming this two-mode network into a one-mode network (LIU and DERUDDER, 2012) as follows (TAYLOR, 2001):

$$
G N C_{a}=\sum_{i, j} v_{a j} \cdot v_{i j}(\mathrm{a} \neq \mathrm{i})
$$

The conjecture behind conceiving the product of service values as a surrogate for actual flows of inter-firm information and knowledge between cities is that the more important the office, the more 
connections there will be with other offices in a firm's network (see however DICKEN and MALMBERG, 2001; JONES, 2002; LAMBREgTS, 2008 and PARNREITER, 2010 translate these into critical appraisal of the assumptions underlying GaWC's model). The limiting case is a city that shares no firms with any other city so that all of its service value products in equation (1) are 0 and it has no connectivity.

As already mentioned, POLYNET extends the scope of the GaWC model to the local scale. In practice, this means that, rather than merely looking at apex of cities and APS firms in the world economy and measuring an urban network at the global scale, POLYNET includes cities and APS firms with a national or regional scope (for more information, see HALL and PAIN, 2006; TAYLOR et al., 2006, 2008, 2009). However, the measurement methodology (equation 2.1) remains the same. Network connectivity and centrality can thus be considered as synonyms, and are commonly expressed in relative terms, which is a city's network connectivity divided by the network connectivity of the most connected city.

Once the network connectivities are calculated, the second step is to combine these scores into a single functional polycentricity index (FPI) to quantify the degree of balance. In the POLYNET project, this is done by taking the average relative connectivity of the non-leading cities, which are the cities with a relative connectivity smaller than 1 (TAYLOR et al., 2006).

\subsection{Limitations and suggestions for alternatives}

POLYNET assesses the functional polycentricity of a MCR by exploring whether it consists of several centres that are more or less equally important in terms of their connectivity to an urban network of aggregated intra-firm relations. As can be seen in (2.1), the factors determining this network connectivity are (i) the number of APS firms in a city (the more APS firms, the more links with offices of the same APS firm in other cities), and (ii) the importance of these APS offices (the more important, the larger the knowledge flows).

A first critical reflection related to this approach is that the presence of offices of the same APS firm in various cities does not necessarily involve flows of knowledge between these cities. Rather than measuring centrality in terms of connectivity to corporate networks of APS firms, an interesting alternative could be to measure centrality in terms of relative importance in APS provision to large companies (i.e. transaction links). It is generally accepted - particularly in management studies - that clients play a key role in the co-production of advanced knowledge and services (BETTENCOURT et al., 2002; AUH et al., 2007, Möller et al., 2008; TRIPPL et al., 2009). It thus seems reasonable to presume that transaction links involve at least some degree of high-end information and knowledge exchange. Therefore, rather than assuming that cities are connected based on the mere co-presence of APS firms, this paper contributes to a recent line of inquiry in urban geography that measures inter-city relations associated with transaction links between APS firms and their clients, which arguably implies a more concrete measure of inter-city networking ${ }^{2}$ (see Rossl et al., 2007; VAN OORT et al., 2010; and LÜTHI et al., 2010 for examples of similar studies). In section 3 of this paper, we explain how such transaction link data were collected and processed.

The second critical reflection relates to the way in which the functional polycentricity index (FPI) in POLYNET is calculated, i.e. by taking the average relative connectivity of the non-leading cities. The problem with this methodology is that the outcome is not only determined by the centrality scores of the constituent centres, but also by the number of centres. As a consequence, the FPIs of urban systems with a different number of constituent centres cannot be compared. Section 4 of this paper 
therefore develops a new index that is both insensitive to the size of the urban system, and that allows for a straightforward interpretation of the results.

The third and final reflection relates to the underlying conceptualization of functional polycentricity, which is described as a situation where there is a certain balance in the relative importance (centrality) of the constituent centres. When applied for instance to transaction link data, this means that in the limiting case of perfect functional polycentricity, all cities provide an equal number of APS. One could however easily imagine a situation in which all cities simply provide an equal number of transaction links to their direct hinterlands. In this case, we could hardly speak of a polycentric MCR, since this urban form - as we explained in the introduction - also involves a certain degree of urban network integration. This means that the constituent cities and towns are to a more or lesser extent functionally networked, which involves a considerable regional cohesion in personal, occupational and corporate relationships (DE GOEI et al., 2010; VAN OORT et al., 2010). In the case of urban network integration, MCRs not only display hierarchical core-periphery relations, but also criss-cross relations between cores or between cities in the periphery. The existence of a certain balance in the centrality of (some of the more important) constituent centres is in other words a necessary condition for a functionally polycentric MCR, but it is not a sufficient one. Another necessary condition relates to the spatial distribution of these inter-city relations. This question could be easily addressed by simply visualising the inter-city relations, which is also done in section 4. However, as we will explain in more detail in section 5, a simple visual analysis is not sufficient. It should be complemented with what DE GoEl et al. $(2010,1156)$ call a formal model to test the structure in spatial interaction patterns. How this is done will also be discussed section 5 .

\section{Case-study: collecting transaction link data}

\subsection{Study area}

The MCR of Central Belgium - as defined by the Belgian team of the POLYNET project (HALL et al., 2006) - comprises a densely populated area straddling the linguistic and administrative borders between the Dutch-speaking Flemish Region, the French-speaking Walloon Region, and the bilingual Brussels-Capital Region. Its economic core consists of an area known as the Flemish Diamond, which is bounded by the agglomerations of Antwerp, Leuven, Brussels and Ghent, and originated as a policy instrument for spatial planning by the Flemish government. The MCR of Central Belgium is dominated by the city of Brussels, which is the capital of both the federal state of Belgium and the European Union, and is also the economic decision-making centre of the country, hosting many financial and corporate headquarters that grant it its world city status (ELMHORN, 1998, 2001; DERUDDER and TAYLOR, 2003; DERUDDER et al., 2010). Antwerp, the second largest city, accommodates one of Europe's largest ports and is also the country's first industrial region. Apart from Brussels and Antwerp, the MCR of Central Belgium also consists of a number of regional cities such as Ghent and Hasselt/Genk in the Dutch-speaking part, and a belt of old industrial towns in the French-speaking Region south of Brussels, including Mons-La Louvière, Charleroi and Liège (AUJEAN et al., 2005; HALL et al., 2006; VANDERMOTTEN et al., 2006).

\subsection{Data collection and processing}

To measure the functional polycentricity of Central Belgium based on transaction links, we collected information on APS procurement by the 300 largest companies located in Belgium ${ }^{3}$. Between $7^{\text {th }}$ of June and $22^{\text {nd }}$ of November 2009, we sent out a questionnaire asking these companies to identify and locate their main business partner for accountancy, advertising, banking/finance, insurance, law, management consultancy and ICT. Of the 300 companies we received 97 completed surveys. Eleven companies indicated that they would not participate in our survey for reasons of confidentiality.

To locate both user and service firms, municipalities' postal codes were collected as initial data. However, to allow for a meaningful comparison with the results of the POLYNET study, we 
aggregated the municipalities to the level of the functional urban regions (FURs) as defined by the Belgian team ${ }^{4}$ (AUJEAN et al., 2005; HALL et al., 2006). The only difference is that we listed Leuven and Mechelen - two secondary agglomerations in the FUR of Brussels - separately as both agglomerations displayed a relatively high number of links compared to both other secondary agglomerations (e.g. St-Niklaas) and other FURs (e.g. Bruges, Charleroi). For companies located outside the MCR, we retained the municipality as spatial unit as POLYNET did not define FURs outside the MCR.

Table 1 lists the distribution of the population (300 companies) and the sample ( 97 companies) by location, administrative region and sector. The last column provides information on the representativeness of the sample by comparing the relative distribution of the sample with the relative distribution of the population. It shows that Walloon companies are somewhat underrepresented in the sample, whereas companies in the Brussels-Capital Region are slightly overrepresented $^{5}$. Regarding the sectoral distribution, only NACE sections D and E are slightly underrepresented, while information and communication firms (NACE section J) are somewhat overrepresented. Overall however, the scores in Table 1 allow us to conclude that the sample of 97 companies is more or less representative for the population of the top-300 companies in Belgium.

\section{$<$ TABLE 1 ABOUT HERE $>$}

The result of our survey was a dataset containing 332 national transaction links ${ }^{6}$ which we then converted into an asymmetric, directional matrix listing the number of transaction links between each of the 17 user cities (FURs or municipalities where the user firms are located) and each of the 15 Belgian service cities (FURs or municipalities where the service firms are located). This matrix is the empirical basis for all further calculations (see Table 2).

\section{<TABLE2 ABOUT HERE>}

\section{An alternative approach for calculating the FPI}

When looking at the list of user and service cities in Table 2, it becomes clear that the geography of transaction links is not restricted to the MCR. Seven of the 17 user cities and five of the 15 service cities are located outside the MCR. Hence, the functional polycentricity of Central Belgium can be measured at two scales: the regional scale, i.e. by considering only the intra-MCR transaction links (white matrix in Table 2), and the national scale, i.e. by extending the white matrix in Table 2 with the user and service cities outside the MCR (grey area). In the first part of this section, we will discuss the methodology for measuring functional polycentricity at the regional scale. A similar procedure is then implemented for the national scale. The results are discussed in the second part of this section.

\subsection{Developing an alternative FPI}

As was explained in section 2.1, measuring the functional polycentricity of a MCR entails two subsequent steps: (i) measuring the centrality of each city/FUR; and (ii) combining these centrality scores into a single index to quantify the degree of balance. For the first step, we focus on the white matrix in Table 2. The rows in this matrix list the total number of services supplied by each FUR to the other FURs in the MCR. A FUR's centrality can be easily computed by taking the sum of the row scores, which equals the total number of transaction links supplied by a FUR (see column 'Regional centrality' in Table 2). Absolute figures are standardized by dividing them by the largest centrality score, which is that of Brussels. These relative centrality scores are listed in the second column of Table 3. 
The second step is to combine the relative centrality scores into one single FPI. To do so, we implement an alternative index that is both insensitive to the size of the MCR and that allows for a straightforward interpretation of individual values. The specification of this functional polycentricity index (FPI) is a variation on the specification of the indices developed in VAN NUFFEL et al. (2010). The FPI is calculated in three steps.

First, we compute for each FUR $i$ the ratio between its relative centrality $\left(R C_{i}\right)$ and the average relative centrality of the other FURs. We call this measure the dominance index $\left(\mathrm{DI}_{\mathrm{i}}\right)$ of city $i$ as it measures the extent to which FUR $i$ is more or less important compared to the average importance of the other FURs:

$$
D I_{i}=\frac{R C_{i}}{\sum_{j=1}^{J} \frac{R C_{j}}{J}}
$$

In a second step, we quantify the overall degree of variance in the DI's by calculating the standard deviation $(\mathrm{SD})^{7}$. The more balanced the importance of the FURs (i.e. the more polycentric the MCR) the smaller the SD. The larger the dominance of one or a few cities, the larger the SD. The SD is however still sensitive to the number of constituent FURs in a MCR. VAN NUFFEL et al. (2010) demonstrate this by calculating the SD for a rank size distribution with an equal number of FURs/cities. In this rank size distribution, the relative centrality of FUR $i\left(R C_{i}^{\prime}\right)$ is $1 / i$ of the relative centrality score of the largest FUR, which is 1 . In other words:

$$
R C^{\prime}{ }_{i}=\frac{1}{i}
$$

If the SD was insensitive to the number of FUR, then adding a FUR $k$ with a $R C^{\prime}$ of $1 / k$ would have no impact on the SD. As this is not the case, the third step is to normalize the SD in such a way that eliminates its sensitivity for the number of FURs, and that statements about individual values can be easily substantiated. The normalization formula is (VAN NUfFEL et al., 2010):

$$
\begin{array}{ll}
F P I=\frac{2-\frac{S D}{S D_{R S}}}{2} & \text { When } S D \leq S D_{R S} \\
F P I=\frac{\frac{S D_{R S}}{S D}}{2} & \text { When } S D \geq S D_{R S}
\end{array}
$$

The outcome is an FPI that, indifferent of the number of FURs in the MCR, results in a value between 0 and 1 , where 0 indicates absolute dominance, 1 points to perfect polycentricity, and 0.5 reflects the rank size distribution ${ }^{2}$ (for a different approach, see LIMTANAKOOL et al. 2007).

\subsection{Evidence for a balance in urban centrality in the MCR of Central Belgium}

This section discusses the results of the functional polycentricity calculations in Table 3, and studies the geography of city-to-city relations using the cartogram in Figure 1. In the cartogram, the area of the MCR is marked by the frame. Intra-MCR transaction links are represented by black arrows, while the grey arrows represent transaction links with or between Belgian cities outside the MCR. The linguistic border between the Flemish Region and the Walloon Region is also indicated on the

\footnotetext{
${ }^{2}$ However, although this normalization introduces 'yardsticks' that allow for a more refined assessment and comparison of the degree of polycentricity in urban systems, two cautionary remarks need to be made. First, these measures can be interpreted as a linear ratio measure: 0,25 does not represent half the strength of 0,50. And second, in this paper we confine ourselves to nodal characteristics, while it could be argued that analyses should also focus on flows characteristics in general and their asymmetry in particular.
} 
cartogram. The orientation of the arrows corresponds to the direction of the service supply (from service city to user city), the borders around the city names correspond to the intra-city links. Cities without intra-city links have no borders. The weight of the arrows and borders is a function of the relative city-to-city service score, which is the absolute city-to-city service score as listed in Table 2 , divided by the largest city-to-city score (in this case 165).

\section{$<$ FIGURE 1 ABOUT HERE $>$}

\section{a. Urban centrality at the regional scale}

When comparing the two highest scores in the second column of Table 3, the figures unmistakably point to the dominance of Brussels. Apparently, large companies located in the MCR of Central Belgium apply to APS firms located in Brussels over four times more than to APS firms located in the second city (Antwerp). The relative centrality of the remaining eight FURs is almost negligible. Ghent appears to be the most 'wanted' regional city for APS procurement, followed first by Hasselt/Genk, Leuven and Mechelen, and then by the Walloon FURs of Liège and Mons-La Louvière, which display an even smaller centrality. Bruges and Charleroi supply no APS, resulting in a relative centrality of 0.

When we take a look at the geography of the individual inter-FUR relations in Figure 1, the most striking feature is probably the weight of the border around Brussels: $57 \%$ of all regional transaction links are procured within this FUR. Since 54 of the 97 companies in our sample are located here (see Table 1), this is however not that much of a surprise. Another notable feature are the arrows between Brussels and Antwerp, indicating the relatively strong link between both FURs. Moreover, Antwerp also displays a relatively high number of intra-city links itself. The only other inter-city relation of some importance is the one between Brussels and Ghent. When looking at the spatial distribution of the remaining service links, we find that Brussels is the only city that is appealed to by each of the other FURs in the MCR. Moreover, apart from one intra-FUR link in Mons-La Louvière, it is also the only service city for all three Walloon FURs. Except for Bruges, Flemish FURs by contrast feature a more regionally intertwined pattern of APS procurement. Interestingly, there are no crossborder links between Flemish and Walloon FURs in either direction ${ }^{8}$.

Taken together, these observations suggest that - as for APS provision to large companies at the regional scale - Central Belgium displays features of a hierarchical urban system with Brussels standing out as dominant service city both in terms of absolute number of links (centrality) and in terms of the spatiality of these links. The latter refers to the fact that Brussels is the only city that provides APS to all other cities in the MCR and that there are no other major links bypassing the city. This is also confirmed when looking at the FPI (see last row in Table 3).

\section{b. Urban centrality at the national scale}

To measure the functional polycentricity of Central Belgium at the national scale, the regional, white matrix in Table 2 is extended with the grey area. This allows answering the following two questions: (i) are there notable changes in the relative importance of the FURs when transaction links to cities outside the MCR are considered; and (ii) can we identify important service cities outside the MCR?

As Table 3 shows, the answer to the first question is clearly negative. Brussels remains the prime service city at the national scale. Its lead on the second city Antwerp even grows as the latter displays a small decrease in relative importance. In fact, Ghent is the only service city who's relative centrality significantly increases at the national scale. The reason for this somewhat remarkable difference between Antwerp and Ghent has however more to do with the demarcation of the MCR - a key issue in spatial analysis known as the Modifiable Area Unit Problem (MAUP) - than with their relative 
importance as service cities at the national scale. As defined by POLYNET, the MCR of Central Belgium excludes a relatively important region in economic terms in the vicinity of Ghent, consisting of cities as Kortrijk, Roeselare and Izegem. Extending the MCR to include these cities would result in a slightly larger relative centrality for Ghent $(0.05$ instead of 0.04$)$ and a slightly smaller relative centrality for Antwerp (0.022 instead of 0.023) at the regional scale.

This is also visible in Figure 1 where the national transaction links clearly display an intertwined pattern in the western part of the country with Ghent and Brussels as the main service cities. A remarkable link in this spatial pattern is the one between Ghent and Estaimpuis since it is the only transaction link in our dataset crossing the linguistic border ${ }^{9}$. Table 3 learns that the FPI at the national scale is only slightly larger than at the regional scale. The MCR of Central Belgium in other words more or less retains it hierarchical structure at the national scale.

To answer the second question regarding the existence of important service cities outside the MCR, we need to look at the relative centrality scores of the five extra-MCR service cities in Table 3. It becomes immediately clear that these are all cities of little significance and that there are no remarkable inter-city links bypassing the MCR. Hence, when it comes to APS procurement by Belgium's largest companies, Brussels is not only the prime service city in the MCR, but also the prime service city at the national scale.

\section{A formal model for testing urban network integration}

\subsection{The gravity model}

As already explained in section 2.2, the existence of a number of cities of more or less equal importance is a necessary but not sufficient condition for functional polycentricity. The spatial distribution of these inter-city relations should also be taken into consideration. In this context, DE GOEl et al. (2010) and VAN OORT et al. (2010) argue that the most extreme form of functional polycentricity can be conceived of as a fully integrated, larger-scale urban network in which there is no effect of the spatial-functional context on inter-firm networks other than the economic mass of sending and receiving localities (the larger their economic mass, the larger the probability of intercity relations) and the physical distance between them (the larger the distance, the smaller the probability). The obvious reason why a simple visualization of urban relations is not sufficient to assess the degree of urban network integration, is that it does not allow for differences in the absolute sizes of municipalities and the distance between them (DE GOEI et al., 2010, 1156). It might for instance be the case that there is a relatively large degree of interaction between Leuven and Mechelen, but that this interaction somewhat 'disappears' because of the - in absolute terms - small size of both cities and because of their close proximity to Brussels.

To formally test the structure in the spatiality of transaction links, we introduce an interaction model that is well-known in spatial analysis and regional science: a geographical application of Newton's gravity model:

$$
I_{i j}=K \frac{M_{i}^{\beta 1} M_{j}^{\beta 2}}{d_{i j}^{\beta 3}}
$$

The dependent variable $I_{i j}$ is the interaction intensity between FURs $i$ and $j$ expressed as the number of transaction links provided by service FUR $j$ to user FUR $i . K$ is a proportionality constant, $M_{i}$ is the mass of the user FUR defined as the total number of transaction links 'demanded' by the FUR and $M_{j}$ is the mass of the service FUR defined as the total number of transaction links 'provided' by the FUR. Finally, $d_{i j}$ is the physical distance between two FURs. For inter-FUR relations, this is calculated as the shortest distance by road between the centres of the core cities of the FURs (e.g. centre of Antwerp to centre of Brussels). This is a good approximation since most of the large companies and APS firms in our survey are located in or in the near proximity of a FUR's core municipality. For intra-FUR 
relations, $d_{i j}$ is calculated by taking two-thirds of the radius of the circle equalling the area $A_{i}$ of the FUR (see BRÖCKER, 1989, and FROST and SPENCE, 1995 for further details):

$$
d_{i i}=\frac{2}{3} \sqrt{\frac{A_{i}}{\pi}}
$$

B1, $B 2$ and $\beta 3$ are parameters to be estimated. $\beta 1$ reflects the potential of a FUR to generate demand for transaction links, B2 reflects the potential of a FUR to provide APS services, and B3 is an impedance factor reflecting the rate of increase of the friction of physical distance.

To estimate these parameters, several regression models have been implemented in the literature. The most simple and therefore most commonly used model is multiple linear regression, often referred to as the log-normal model because of its use of natural logarithms. More advanced models include Poisson regression (FLOWERDEW and AITKIN, 1982) and zero-inflated negative binomial (ZNB) regression (BURGER et al., 2009; DE GOEl et al., 2010 and VAN OORT et al., 2010). Contrary to the lognormal model, where the interaction variables are assumed to be normally distributed around the estimate, the Poisson and ZNB model are count models, which treat the interaction variable as the outcome of a discrete probability process. The main difference between Poisson regression and ZNB regression is that the latter allows for heteroscedasticity and overdispersion (when the conditional variance is larger than the conditional mean), and also deals with excessive numbers of zero counts (when the incidence of zero counts is greater than would be expected by the negative binomial regression model). Given the problems related to the use of the log-normal model (see FLOWERDEW and AITKIN, 1982 for an overview) this paper only considers the count models.

To select the best fitting regression model (Poisson or negative binomial, zero-inflated or non zeroinflated), we test for overdispersion and zero-inflation (cf. VAN OORT et al., 2010). The former is done by means of a likelihood ratio test of overdispersion $\alpha$ (CAMERON and TRIVEDI, 1986), the latter by means of a Vuong statistic (VUONG, 1989). The results are summarized in Table 4. Overall, the values suggest that the negative binomial fit is not significantly better than the Poisson fit (i.e. the log likelihood of the negative binomial model equals that of the Poisson model, so there is no indication for overdispersion), and that the zero-inflated Poisson model is not significantly better than the Poisson model (i.e. there is no indication of zero inflation) ${ }^{10}$. This paper therefore implements the Poisson model to estimate the parameters of the gravity model.

\section{$<$ TABLE 4 ABOUT HERE $>$}

Poisson regression is estimated by means of maximum likelihood estimation techniques. The observed interaction intensity between two cities has a Poisson distribution with a conditional mean $\mu_{\mathrm{ij}}$ that is a function of the independent variables (VAN OORT et al., 2010, 736):

$$
\begin{gathered}
\operatorname{Pr}\left[I_{i j}\right]=\frac{\exp \left(-\mu_{i j}\right) \mu_{i j}^{I_{i j}}}{I_{i j} !} \\
\text { With } \mu_{i j}=\exp \left[K+\beta_{1} \ln \left(M_{i}\right)+\beta_{2} \ln \left(M_{j}\right)+\beta_{3} \ln \left(d_{i j}\right)\right]
\end{gathered}
$$

This model estimates the gravity model in its most basic form. To test the assumption of urban network integration, it can be extended by including other variables (DE GOEl et al., 2010; VAN OORT et al., 2010). Previously, we argued that, if Central Belgium can be characterized as an integrated urban network, then inter-city relations are solely determined by the economic mass of cities and the physical distance between them, and not by the spatial-functional context. In other words, there should be no difference in the relative strength of different types of spatial relations (regimes, see DE 
GoEl et al., 2010; VAN OORT et al., 2010). For the case of Central Belgium, we can distinguish six regimes:

(i) Transaction relations within FURs,

(ii) Transaction relations between FURs,

a. Inter-core relations (transaction links between Antwerp and Brussels),

b. Core-periphery relations (APS provision by Antwerp or Brussels to the other FURs),

c. Periphery-core relations (APS provision by peripheral FURs to Antwerp or Brussels),

d. Periphery-periphery relations (transaction links between peripheral FURs).

(iii) Transaction links crossing the linguistic border (transaction links between strictly Flemish FURs and strictly Walloon FURs, see Figure 1).

By analogy with VAN OORT et al. (2010), we can then rephrase the overall condition for urban network integration into three formally testable conditions:

(i) Intra-FUR interdependency should not be stronger than interdependencies between FURs in the MCR of Central Belgium. This is tested by introducing a dummy variable D1 for inter-FUR transaction links,

(ii) There should be no observable hierarchy in the different types of inter-FUR interdependencies. This is tested by introducing dummy variables D2 for inter-core transaction links, D3 for core-periphery transaction links, and D4 for inter-periphery transaction links,

(iii) There should be no effect of the linguistic border on the interdependencies between Flemish and Walloon FURs. This is tested by introducing dummy variable D5 for cross-border transaction links.

\subsection{Evidence for urban network integration in the MCR of Central Belgium}

Model 1 in Table 4 represents the basic gravity model. It only considers the economic mass of the user FUR and the service FUR, and the distance between both FURs to estimate the regression parameters. As was to be expected, the results first of all show that there is a marked direct correlation between the economic mass of both the user FUR $\left(M_{i}\right)$ and the service FUR $\left(M_{j}\right)$ on the one hand, and the flow frequency $\mathrm{l}_{\mathrm{ij}}$ between both FURs on the other hand. As indicated by the estimates, which can be interpreted as elasticities (VAN OORT et al., 2010), the impact of $M_{j}$ on the flow frequency is hereby larger than the impact of $M_{i}$ : when the economic mass of the user city $M_{i}$ increases with one percent, then the flow frequency between both cities is predicted to increase with 0.82 percent, whereas a similar increase in the mass of the service city $M_{j}$ would result in an 
increase of the flow frequency between both cities with 0.95 percent. Second, as was also to be expected, there is a marked inverse correlation between the distance $d_{i j}$ between both FURs on the one hand and the flow frequency $I_{i j}$ on the other hand: when $d_{i j}$ increases with one percent, then $I_{i j}$ decreases with 1.32 percent.

Model 2 tests the first condition for spatial integration, which asserts that the intra-FUR interdependency should not be stronger than the inter-FUR interdependency. This condition was tested by introducing a dummy variable D1, which equals 0 in the case of intra-FUR relations and 1 in the case of inter-FUR relations. The estimate for D1 shows that this first condition is not met. When controlling for economic mass and distance, the flow frequency decreases significantly when the interaction is between two FURs instead of within the same FUR. More specifically, the predicted flow intensity within the same FUR is over 136 percent larger compared to the predicted flow intensity between two FURs. This can be calculated by taking the natural exponent of the estimate of the dummy variable. The log likelihood, McFadden's Adjusted $\mathrm{R}^{2}$, and AIC in Table 4 indicate that model 2 better estimates the data than model 1 .

The second condition states that there should be no observable hierarchy in the different types of inter-FUR interdependencies. This condition is tested in model 3. In analogy to VAN OORT et al. (2010), we take periphery-core relations as the reference category, as it is conceptually the weakest type of urban interdependency. By computing the estimates for the three dummy variables D2 (equals 1 in the case of inter-core relations), D3 (equals 1 in the case of core-periphery relations), and D4 (equals 1 in the case of inter-periphery relations), we can compare the relative strength of the different types of inter-FUR interdependencies. A Wald test is implemented to formally test this assumption (cf. VAN OORT et al., 2010). The results of the Wald test and the scores in Table 4 indicate that this condition is also not met, although the results are rather counterintuitive. The only estimate that is statistically significant is the one for inter-periphery relations (D4). According to Table 4, the number of predicted flows for inter-periphery relations is over 277 percent higher than the number of predicted flows for periphery-core relations, whereas for inter-core relations, the number of predicted flows is only 13 percent higher. For core-periphery relations, the results are even more counterintuitive as the number of predicted flows for core-periphery relations is nearly 9 percent lower than for peripherycore relations. The latter two estimates are however not statistically significant.

Finally, model 4 tests the third condition for spatial integration, which states that there should be no impact of the linguistic border on the interdependencies between FURs. The estimate for D5 seems to suggest that there is a marked, inverse correlation between this variable and $\mathrm{I}_{\mathrm{ij}}$, indicating that when controlling for economic mass and distance - the expected flow intensity decreases in the case of cross-border transaction links. However, as the p-value of the estimate shows, the impact of D5 on the interaction intensity is not statistically significant. The reason why this foreseeable impact is not confirmed by our model is probably because of the lack of information that is needed to allow for a more precise estimation of this parameter.

Overall, this formal test adds to our previous finding that Central Belgium does not (yet) function as a functionally polycentric MCR. Despite the relative good model fit, the interpretation of the results is however not always straightforward. This is probably due to the limited number of city-to-city relations in our database (i.e. 100 of which 71 zero's), the relatively high share of intra-FUR relations in Brussels (over 56 percent of all transaction links), and the small number of transaction links for smaller FURs. A more elaborate data collection is therefore needed to allow for more a more robust formal test.

\section{Conclusion and discussion}

This paper introduces an alternative approach to measure functional polycentricity through the lens of advanced producer services, and implements it to the case of Central Belgium. In doing so, we 
distinguish between two necessary conditions for functional polycentricity. The first condition focuses on the nodes/cities and states that there should be a certain balance in their relative importance (i.e. centrality). This was tested by calculating the proposed alternative FPI. The results indicated that the first condition for polycentricity is not met. Contrary to the POLYNET study, in which Central Belgium was described as a duopoly with Antwerp rivalling Brussels, our results suggest that, when it comes to service procurement by large companies in Belgium, the MCR of Central Belgium displays features of a hierarchical urban system with Brussels as main service centre both at the regional and the national scale.

Merely calculating the FPI does however not account for the spatiality of the inter-city relations. The second necessary condition for functional polycentricity therefore states that there should be evidence for urban network integration, which is manifested in the existence of criss-cross relations between cities of different size. To assess the extent to which Central Belgium satisfies the second condition for functional polycentricity, we implemented a formal model that tests three more specific requirements for urban network integration. None of these requirements were met: (i) intraFUR interdependencies appeared to be stronger than inter-FUR interdependencies, (ii) we observed a hierarchy in the different types of inter-FUR relations, and (iii) we also found a rather strict spatial division in service procurement between the Flemish and Walloon Region.

Overall, these results suggest that the urban geography of service procurement by large companies does not attest to the existence of a functionally polycentric MCR in Central Belgium. In this case, the functional polycentricity (also coined 'urban network') concept, which has been proposed as the contemporary alternative for central place thinking (BATTEN, 1995; CAPELLO, 2000; CAMAGNI and CAPELLO, 2004; MeIJERS, 2007), is not (yet) suitable for describing the geography of the Belgian urban system (see VAN OORT et al., 2006, 2010 for similar findings in the Randstad). On the other hand, however, it is clear that a traditional Christallerean approach is also no longer appropriate. This is particularly true for the Flemish Region, where we observed a more regionally intertwined pattern of transaction links. The two main paradigms in urban geography - the Christallerean hierarchy and the concept of urban networks - are thus neither completely fit for describing the geography of the Belgian urban system, at least not for the case of urban centrality in advanced producer service provision. Rather, both paradigms seem to make an 'uneasy reunion' (HALL and PAIN, 2006, 12). On the one hand, Central Belgium displays criss-cross relations resulting in overlapping urban spheres of influence which at times even supersede national borders. On the other hand, there is also a recognizable urban hierarchy with Brussels as the main service city whose urban influence stretches across the whole national economy and beyond.

Although these conclusions are rather straightforward, it is nevertheless important to interpret them in light of the limited scope of our case-study. First of all, as we already suggested in the previous section, a more elaborate data collection is needed to capture the urban geography of service procurement in more detail and to allow for a more robust analysis of the geography of the Belgian urban system. Second, our analyses assess the urban structure of Central Belgium at one point in time. However, as DE GOEl et al. (2010) notice, although city-systems are not 'born' polycentric, they may be evolving in that direction. A longitudinal study is therefore needed to explore whether this might be the case for Central Belgium. Third, while Central Belgium is perhaps not functionally polycentric in terms of service procurement, there are many other sectors and functions for which this might be the case. One of the basic assumptions of the urban network paradigm is that urban network integration is the result of a certain degree of urban specialization and, hence, complementarity. This provides a rather different perspective for studying functional polycentricity. When retaining the focus on the APS sector, an interesting question in this context might be whether Antwerp is for instance specialized in other types of services (e.g. port-related services, design sector...) than Brussels, making both cities complementary in serving the Belgian market. Given that the likely presence of port-related services in Antwerp not picked up in this and most other studies, it is even imaginable that the Belgian urban network is in fact a duopoly. From a broader economic 
perspective, i.e. not only focusing on urban specialization in the APS sector but also on other sectors, the picture might be even more different (see BURGER, 2011 for an overview). In this case, Central Belgium could actually display features of functional polycentricity as it allows cities to be specialized - and hence complementary - in different economic sectors. MEIJERS (2009) provides empirical findings that confirm this assumption, demonstrating that government-related activities are particularly concentrated in Brussels, transport services in Antwerp, and research and education in Ghent and Leuven. However, further research is needed however to explore this and the previously mentioned questions in further detail.

\section{Notes}

${ }^{1}$ For the remainder of this paper, we employ the term advanced producer services (APS) rather than knowledge-intensive business services (KIBS). There are two reasons for this: (i) this paper to some extent conceptually builds on the literature on global cities and the world city network in which APS is more commonly used than KIBS; and (ii) apart from the usual KIBS such as management consultancy, law, advertising... our analysis also includes financial services and insurance.

${ }^{2} \mathrm{~A}$ similar argument has been made in studies that measure intercity relations based on ownership links in multinational companies (cf. Alderson and BECKFIELD, 2004; ROZENBLAT and PUMAIN, 2007; WALL and VAN DER KNAAP, 2010).

${ }^{3}$ Belgium's top 300 firms as listed on the website of Trends Top (http://trendstop.rnews.be, Accessed: 11 May 2009). This ranking is based on corporate turnover figures for fiscal year 2007.

${ }^{4} \mathrm{~A}$ FUR comprises an economic core and a ring consisting of those neighbouring municipalities in which at least $10 \%$ of the working population commutes to the core on a daily bases. The economic core of a FUR is either a number of neighbouring municipalities with an employment density in excess of 700 jobs per $\mathrm{km}^{2}$ and having a total of at least 35000 jobs; or a municipality with over 35 000 jobs plus its neighbouring municipalities with an employment density exceeding 700 jobs per $\mathrm{km}^{2}$. In the Belgian case, eight contiguous FURs make up the MCR. For more details on the geographical definition of the MCR of Central Belgium, see AUJEAN et al. (2005).

${ }^{5}$ As our questionnaire was written in Dutch and English but not in French, it has been suggested that the underrepresentation of Walloon firms might be the result of a language bias. There are two reasons why we think this might be the case only to some extent. First of all, the bilingual (though in practice predominantly French speaking) Brussels Capital Region is overrepresented in our sample. Second, instead of considering the location of the companies to test the assumption of a language bias, it might be more useful to take into account the (native) language of the CEO/CFO or personal assistant who initially received and dealt with our survey.

${ }^{6}$ It should be noted that, on top of the 332 national links, our dataset also included 26 international links with service cities abroad.

${ }^{7}$ The reason why we calculate the SD of the DI's instead of the SD of the RC's is that - as will become clear in the third step of our measurement methodology - we need the SD to become infinite in the limiting case of absolute dominance.

${ }^{8}$ Although Brussels is situated north of the linguistic border, it officially constitutes a bilingual region. Therefore, the transaction links between Brussels and either Walloon or Flemish FURs or are not considered as cross-border linkages.

${ }^{9}$ In her study of the impact of the Belgian linguistic border on the spatial configurations of inter-firm networks of small- and medium-sized enterprises located in the Flemish-Walloon border region, STRIHAN (2008) reported similar observations. She noted that corporate networks do have ties crossing the border, but that these are few and - in her study - predominantly develop along familybased or ethnic axes of solidarity.

${ }^{10}$ The only exception is model 2, where the Vuong statistic indicates that the zero-inflated Poisson fit is better. However, as the expected number of zero's in both regression models is the same (i.e. 75 compared to 71 observed zero's), this difference in model fit cannot be explained by a better fit for zero-inflation. Hence, also for model 2, a Poisson regression appeared to be the most appropriate model. 


\section{References}

ALDERSON A.S., BECKFIELD J. (2004) Power and position in the world city system, American Journal of Sociology 109, 811-851.

AUH S., BELL S.J., MCLEOD C.S. and SHIH E. (2007) Co-production and customer loyalty in financial services, Journal of Retailing 83, 359-370.

AUJEAN L., CASTIAU E., ROELANDTS M. and VANDERMOTTEN C. (2005) POLYNET Action 1.1.: Commuting and the Definition of Functional Urban Regions: Central Belgium. Institute of Community Studies/The Young Foundation and POLYNET Partners, London. http://www.polynet.org.uk/

BATTEN D.F. (1995) Network cities: creative urban agglomerations for the 21st century, Urban Studies 32, 313-327.

BETTENCOURT L.A., OSTROM A.L., BROWN S., W. and ROUNDTREE R. I. (2002) Client co-production in knowledge-intensive business services, California Management Review 44, 100-128.

BRÖCKER J., (1989) How to eliminate certain defects of the potential formula, Environment and Planning, A 21, 817-830.

BURGER, M.J. (2011) Structure and cooptation in urban networks. PhD Thesis, Erasmus University Rotterdam. Available online from http://repub.eur.nl/res/pub/26178/.

BURGER M., VAN OORT F.G. and LINDERS G.J. (2009) On the specification of the gravity model of trade: zero's, excess zero's and modified Poisson estimation. Spatial Economic Analysis 4, 167190.

BURGER M.J. and MEIJERS E.J. (2012) Form follows function? Linking morphological and functional polycentricity, Urban Studies 49, 1127-1149.

CAMAGNI R. and CAPELLO R. (2004) The city network paradigm: theory and empirical evidence, in

CAPELLO R. and NIJKAMP P. (Eds) Urban Dynamics and Growth, pp. 495-529. Elsevier, Amsterdam.

CAMERON A.C., TRIVERDI P.K. (1986) Econometric models based on count data: comparisons and applications of some estimators and tests, Journal of Applied Econometrics 1, 29-53.

CAPELLO R. (2000) The city network paradigm: measuring urban network externalities. Urban Studies 37, 1925-1945.

CASTELLS M. (1996) The Rise of the Network Society. Blackwell, Oxford.

DE GOEI B., BURGER M.J., VAN OORT F. and KITSON M. (2010) Functional polycentrism and urban network development in the Greater South East, United Kingdom: evidence from commuting patterns, 1981-2001, Regional Studies 44, 1149-70.

DERUDDER B. and TAYLOR P.J. (2003) The global capacity of Belgium's major cities: Antwerp and Brussels compared, Belgeo 4, 459-476.

DERUDDER B., TAYLOR P.J., NI P., DE VOS A., HOYLER M., HANSSENS H., BASSENS D., HUANG J., WITLOX F. and YANG X. (2010) Pathways of growth and decline: connectivity changes in the world city network, 2000-2008, Urban Studies 47, 1835-1841.

DERUDDER B., TAYLOR P.J., WITLOX F. and CATALANO G., (2003) Hierarchical tendencies and regional patterns in the world city network: A global urban analysis of 234 cities, Regional Studies 37, 875886.

DICKEN P. and MALMBERG A. (2001) Firms in territories: a relational perspective, Economic Geography 77, 345-363.

ELMHORN C. (1998) Brussels in the European economic space: the emergence of a world city?, Bevas/Sobeg 1, 79-101.

ELMHORN C. (2001) Brussels: a Reflexive World City. Almqvist and Wiksell International, Stockholm.

FLOWERDEW R. and AITKIN M. (1982) A method of fitting the gravity model based on the Poisson distribution, Journal of Regional Science 22, 191-202.

FROST M.E. and SPENCE N.A. (1995) The rediscovery of accessibility and economic potential: the critical issue of self-potential, Environment and Planning, A 27, 1833-1848.

HALL P. (1999) Planning for the mega-city: a new Eastern Asian urban form?, in BROTCHIE J., NEWTON P., HALL P. and DICKEY J. (Eds) East-West Perspectives on 21st Century Urban 
Development: Sustainable Eastern and Western Cities in the New Millennium, pp. 3-36. Ashgate, Aldershot.

HALL P. and PAIN K. (2006) The Polycentric Metropolis: Learning from Mega-City Regions in Europe. Earthscan, London.

HALL P., PAIN K. and GREEN N. (2006) Anatomy of the polycentric metropolis: eight mega-city regions in overview, in HALL P. and PAIN K. (Eds) The Polycentric Metropolis. Learning from Mega-City Regions in Europe, pp. 20-52. Earthscan, London.

HOYLER M., KLOOSTERMAN R. C. and SOKOL M. (2008) Polycentric puzzles - emerging mega-city regions seen through the lens of advanced producer services, Regional Studies 42, 1055-1064.

JONES A. (2002) The 'global city' misconceived: the myth of 'global management' in transnational service firms, Geoforum 33, 335-350.

KLOOSTERMAN R.C. and MUSTERD S. (2001) The polycentric urban region: towards a research agenda, Urban Studies 38, 623-633.

LAMBREGTS B. (2008) Geographies of knowledge formation in mega-city regions: Some evidence from the Dutch Randstad, Regional Studies 42, 1173-1186.

LIMTANAKOOL N., DIJST M., and SCHWANEN T. (2007) A theoretical framework and methodology for characterising National Urban Systems on the basis of flows of people: Empirical evidence for France and Germany, Urban Studies 44, 2123-2145.

LIU X. and DERUDDER B. (2012) Two-mode networks and the interlocking world city network model: a reply to Neal, Geographical Analysis 44, 171-173.

LÜTHI S., THIERSTEIN A. and GOEBEL V. (2010) Intra-firm and extra-firm linkages in the knowledge economy: the case of the emerging mega-city region of Munich, Global Networks 10, 114-137.

MEIJERS E.J. (2007) From central place to network model: theory and evidence of a paradigm change, Tijdschrift voor Sociale en Economische Geografie 98, 245-259.

MEIJERS E.J. (2007) Clones or complements? The division of labour between the main cities of the Randstad, the Flemish Diamond and the Rhein-Ruhr Area. Regional Studies 41, 889-900.

MEIJERS, E.J. (2008) Measuring polycentricity and its promises, European Planning Studies 16, 13131323.

MEIJERS E.J. and BURGER M.J. (2010) Spatial Structure and Productivity in U.S. Metropolitan Areas, Environment and Planning A 42, 1383-1402.

MÖLLER K., RAJALA R. and WESTERLUND M. (2008) Service innovation myopia? A new recipe for client-provider value creation, California Management Review 50, 31-48.

PARNREITER C. (2010) Global Cities in Global Commodity Chains: Exploring the Role of Mexico City in the Geography of Global Economic Governance, Global Networks 10, 35-53.

ROZENBLAT C. and PUMAIN D. (2007) Firm linkages, innovation and the evolution of urban systems, in TAYLOR P.J., DERUDDER B., SAEY P. and WITLOX F. (Eds), Cities in Globalization, pp. 130-156. Routledge, London.

ROSSI E.C., BEAVERSTOCK J.V. and TAYLOR P.J. (2007) Transaction links through cities: 'decision cities' and 'service cities' in outsourcing by leading Brazilian firms, Geoforum 38, 628-642.

SASSEN S. (2001) The Global City. New York, London, Tokyo. Princeton University Press, Princeton.

SCOTT A. J. (Ed) (2001) Global City-Regions: Trends, Theory, Policy. Oxford University Press, Oxford.

STRIHAN A. (2008) A network-based approach to regional borders: the case of Belgium, Regional Studies 42, 539-554.

TAYLOR P.J. (2001) Specification of the world city network, Geographical Analysis 33, 181-194.

TAYLOR P.J. (2004) World City Network: A Global Urban Analysis. Routledge, London.

TAYLOR P.J. and ARANYA R. (2008) A global 'Urban roller coaster'? Connectivity changes in the world city network, 2000-2004, Regional Studies, 42, 1-16.

TAYLOR P. J., EVANS D. and PAIN K. (2006) Organization of the polycentric metropolis: corporate structures and networks, in HALL P. and PAIN K. (Eds) The polycentric metropolis: learning from mega-city regions in Europe, pp. 53-64. Earthscan, London. 
TAYLOR P. J., EVANS D. M. and PAIN K. (2008) Application of the interlocking network model to mega-city-regions: measuring polycentricity within and beyond city-regions, Regional Studies 42, 1079-1093.

TAYLOR P. J., EVANS D.M., HOYLER M., DERUDDER B. and PAIN K. (2009) The UK Space Economy as Practised by Advanced Producer Service Firms: Identifying Two Distinctive Polycentric CityRegional Processes in Contemporary Britain, International Journal of Urban and Regional Research 33, 700-718.

TRIPPL M., TÖDTLING F. and LENGAUER L. (2009) Knowledge sourcing beyond buzz and pipelines: evidence from the Vienna software sector, Economic Geography 85, 443-462.

VANDERMOTTEN C., ROELANDTS M., AUJEAN L. and CASTIAU E. (2006) Central Belgium: polycentrism in a federal context, in HALL P. and PAIN K. (Eds) The Polycentric Metropolis: Learning from MegaCity Regions in Europe, pp. 146-153. Earthscan, London.

VAN NUFFEL N., SAEY P., DERUDDER B., DEVRIENDT L. and WITLOX F. (2010) Measuring hierarchical differentiation: connectivity and dominance in the European urban network, Transportation Planning and Technology 33, 343-366.

VAN OORT F., BURGER M. and RASPE O. (2010) On the economic foundation of the urban network paradigm: spatial integration, functional integration and economic complementarities within the Dutch Randstad, Urban Studies 47, 725-48.

VAN OORT F., VAN BRUSSEL J., RASPE O., BURGER M., VAN DINTEREN J. and VAN DER KNAAP B. (2006) Economische netwerken in de regio. NAi Uitgevers, Rotterdam.

VUONG Q. H. (1989) Likelihood ratio tests for model selection and non-nested hypotheses. Econometrica 57, 307-333.

WALL R. and VAN DER KNAAP B. (2011) Sectoral Differentiation and Network Structure Within Contemporary Worldwide Corporate Networks, Economic Geography 87, 267-308. 